\title{
AS CONTRIBUIÇÕES DO PLANEJAMENTO E DA GESTÃO FINANCEIRA PARA A OTIMIZAÇÃO DOS NEGÓCIOS DAS MICRO E PEQUENAS EMPRESAS (MPES)
}

\section{THE CONTRIBUTIONS OF PLANNING AND FINANCIAL MANAGEMENT FOR THE OPTIMIZATION OF MICRO AND SMALL BUSINESSES (SMES)}

\author{
Diego José Casagrande - diegojcasagrande@ gmail.com \\ Especialista em Gestão Empresarial pela FGV - Ribeirão Preto - São Paulo - Brasil
}

\begin{abstract}
RESUMO
Diante do alto nível de competitividade imposto pela atuação dos contextos estratégico e econômico, a adoção de ferramentas administrativas eficazes tornou-se algo indispensável a fim de otimizar e o controlar as atividades empresariais. Ao enfatizar o universo de atuação que engloba as Micro e Pequenas Empresas (MPEs), verifica-se que o delineamento e a implantação de mecanismos gerenciais devidamente consolidados são fundamentais para a manutenção e a eficácia desses empreendimentos. Diante deste cenário, o objetivo central deste artigo é apresentar as principais contribuições do planejamento e da gestão financeira para a otimização e o controle das atividades e processos das MPEs. Deste modo, buscou-se compreender o viés analítico conceitual das finanças e incorporá-lo à vertente dos micro e pequenos empreendedores. O trabalho em questão foi desenvolvido por meio de pesquisa bibliográfica e, através do referencial teórico obtido, considerou-se que o gerenciamento adequado dos recursos financeiros é uma condição primordial para a sobrevivência das MPEs.
\end{abstract}

Palavras-chave: Ferramentas administrativas. Gestão financeira. Micro e Pequena Empresa.

\begin{abstract}
Given the high level of competitiveness imposed by the strategic and economic contexts, the adoption of effective administrative tools has become indispensable in order to optimize and control business activities. In emphasizing the universe of action that encompasses Micro and Small Enterprises (SMEs), it is verified that the design and implementation of duly consolidated management mechanisms are fundamental for the maintenance and effectiveness of these enterprises. Given this scenario, the main objective of this article is to present the main contributions of planning and financial management for the optimization and control of the activities and processes of MSEs. In this way, we sought to understand the conceptual analytical bias of finances and to incorporate it to the micro and small entrepreneurs. The work in question was developed through bibliographical research and, through the theoretical reference obtained, it was considered that the adequate management of financial resources is a primordial condition for the survival of MSEs.
\end{abstract}

Keywords: Administrative tools. Financial management. Micro and Small Business.

\section{DOI:}




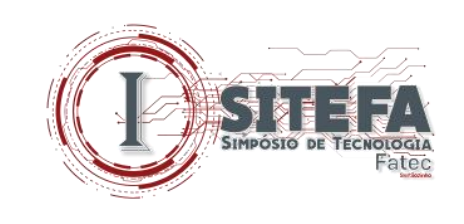

\section{INTRODUÇÃO}

Segundo o Art. 3 da Lei Geral da Microempresa e Empresa de Pequeno Porte (Lei $\mathrm{n}^{\mathrm{o}}$ 123/2006), consideram-se microempresas (ME) ou empresas de pequeno porte (EPP) as sociedades empresárias, as sociedades simples, as empresas individuais de responsabilidade limitada e os empresários a que se referem o art. 966 da Lei no 10.406, de 10 de janeiro de 2002 (Código 11 Civil). Estas, por sua vez, devem estar devidamente registradas junto ao Registro de Empresas Mercantis ou no Registro Civil de Pessoas Jurídicas.

No caso específico das microempresas, a mesma deverá auferir, em cada ano calendário, uma receita bruta igual ou inferior a $\mathrm{R} \$ 360.000,00$. Em relação à empresa de pequeno porte, por sua vez, a mesma poderá auferir uma receita bruta superior a $R \$$ 360.000,00 e igual ou inferior a $\mathrm{R} \$ 3.600 .000,00$ em cada ano-calendário (BRASIL, 2006).

De acordo com Marques (2009), as micro e pequenas empresas (MPEs) representam a maioria das empresas brasileiras. Deste modo, as suas características de atuação em âmbito global as tornam tão importantes quanto as grandes corporações. Devido à flexibilidade de se moldarem às contínuas exigências mercadológicas, as MPEs contribuem efetivamente para o desenvolvimento socioeconômico do país. Além disso, as mesmas introduzem inovações constantes em seus negócios, contribuindo assim diretamente com seus segmentos de atuação.

De acordo com Campos (2016), as MPEs representam 99\% das empresas existentes no país, sendo responsáveis por $27 \%$ do Produto Interno Bruto (PIB) e por mais da metade dos empregos formais existentes no Brasil. Trata-se, assim, um setor de enorme importância para a economia, pois fomenta a geração de renda e impulsiona o ambiente global de negócios. Mediante esta perspectiva, Azevedo e Leone (2011) ressaltam que, por se caracterizem como importantes fomentadoras de emprego e de renda para uma grande massa de trabalhadores, as MPEs constituem-se num grande sustentáculo socioeconômico em vários países.

No âmbito brasileiro, as MPEs se configuram como um dos principais pilares de desenvolvimento da economia nacional. Os empreendimentos em questão, além de possuírem grande capacidade e absorção no aspecto da geração de empregos, também fixam os seus estabelecimentos desconcentrados geograficamente, demonstrando assim um nível significativo de flexibilidade e abrangência (MARQUES, 2009). 


\section{(1) 3 mex}

\section{O PAPEL ESTRATÉGICO DAS MPES NO CONTEXTO BRASILEIRO}

De acordo com Tozzini (2001), embora as MPEs chamem menos atenção se comparadas às grandes corporações nacionais, as suas contribuições específicas para o desenvolvimento social e mercadológico as colocam como um componente vital da economia. Neste sentido, as MPEs assumem um papel cada vez mais importante no cenário em que atuam, sendo essenciais para a integração de vários atores em diferentes cadeias produtivas.

Segundo Vilga, Farah e Giuliani (2005), a crise econômica mundial e a recessão da economia brasileira forçaram as médias e grandes empresas instaladas no Brasil a reduzirem os seus gastos. Diante deste cenário, as MPEs expandiram os seus negócios gradativamente, tendo em vista o dinamismo de funcionamento que possuem. A redução de investimentos por parte das grandes corporações fez com que as MPEs, consequentemente, adquirissem cada vez mais representatividade na economia nacional, expandindo assim os seus negócios.

Ainda na visão dos autores, o crescimento significativo das MPEs ocorreu a partir da década de 1970. Nas décadas seguintes, consequentemente, as mesmas passaram a assumir, gradativamente, um papel fundamental no cenário socioeconômico brasileiro. Por possuírem inúmeras características estruturais que as distinguem das empresas de médio e grande porte, as MPEs necessitam de um enfoque específico de gerenciamento, sendo este caracterizado pela flexibilidade das ações administrativas no âmbito do planejamento e controle.

De acordo com Oliveira (2006, p. 5), “as pequenas empresas desempenham um papel de fundamental importância no crescimento e maturação de uma economia". Ainda segundo o autor, por normalmente produzirem em menor escala, as MPEs possuem maior possibilidade de responder às oportunidades mais rapidamente $\mathrm{e}$ atender a mercados distintos e especializados, sendo assim altamente flexíveis em suas atividades.

As MPEs, em sua essência, quase sempre são de propriedade de um único indivíduo ou de um grupo considerado restrito de pessoas. Por este motivo, as mesmas são normalmente administradas por seus proprietários de maneira independente, sendo que estes assumem o papel de centralização no âmbito dos processos decisórios e gerenciais (OLIVEIRA, 2006).

Na perspectiva de Padoveze e Martins (2014), as MPEs representam, no cenário contemporâneo, a maior parcela de empreendimentos formais no Brasil, correspondendo assim a $48 \%$ da mão de obra ocupada no país. Confirmando este cenário, o Sebrae (2015) 


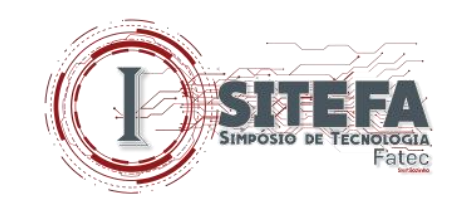

ressalta que as micro e pequenas empresas são caracterizadas como os empreendimentos de maior faturamento anual, além de gerarem um índice de empregabilidade significativo.

Mediante este cenário, torna-se evidente o fato de que as MPEs são as organizações que apresentam a maior possibilidade de fazer com que a economia nacional evolua, visando assim aproximar o Brasil dos países desenvolvidos. Tendo em vista a representatividade das MPEs no Brasil, o gráfico 1 demonstra a distribuição das mesmas por setores econômicos.

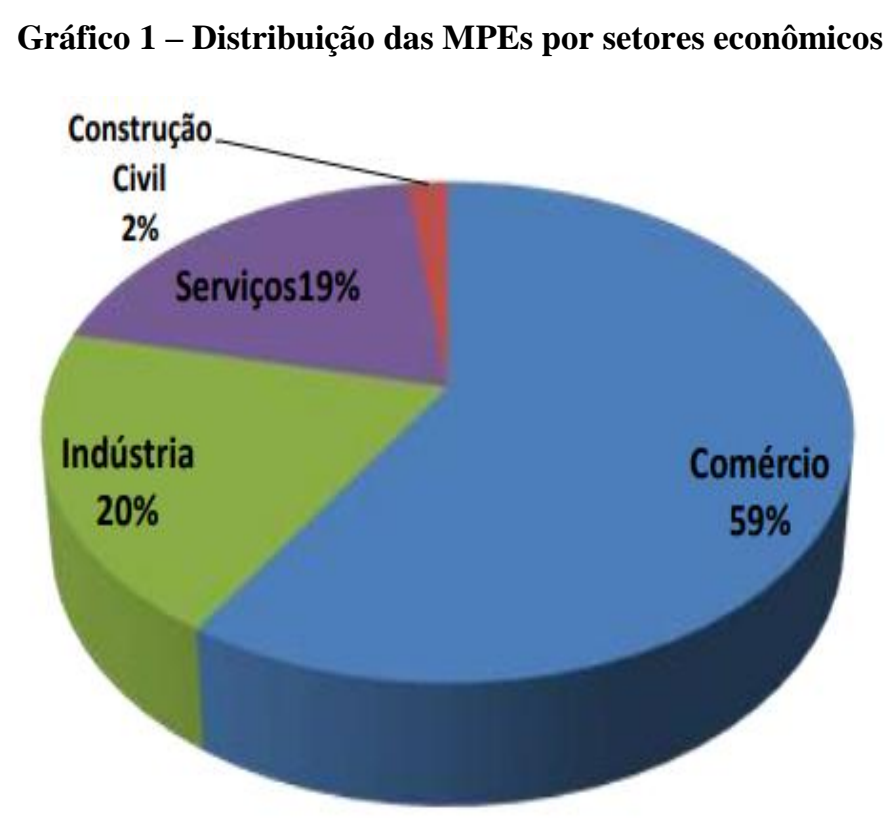

Fonte: Sebrae (2011)

No período estabelecido entre 2000 e 2011, as micro e pequenas empresas ultrapassaram a barreira dos seis milhões de estabelecimentos no Brasil. Neste período, o crescimento médio do número de MPEs foi de 3,7\% a.a. Entre 2000 e 2005, o crescimento médio das MPEs foi de 4,8\% a.a., enquanto o ritmo de crescimento entre 2005 e 2011 foi de 2,8\% a.a. Entre 2000 e 2011, as micro e pequenas empresas criaram sete milhões de empregos com carteira assinada, elevando assim o total de empregos nestas empresas de 8,6 milhões de postos de trabalho em 2000 para 15,6 milhões no ano de 2011 (SEBRAE; DIEESE, 2012).

De acordo com o Sebrae (2014), as Micro e Pequenas Empresas (MPEs) vêm adquirindo, ao longo dos últimos 30 anos, uma importância crescente no país. No contexto contemporâneo, as MPEs já são as principais geradoras de riqueza no comércio no Brasil 


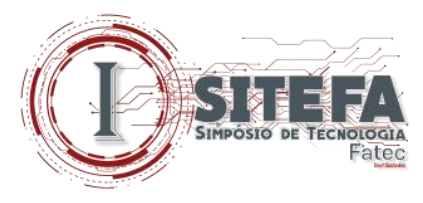

(53,4\% do PIB deste setor). No PIB da indústria, a participação das micro e pequenas $(22,5 \%)$ já se aproxima das médias empresas $(24,5 \%)$. Já no setor de Serviços, mais de um terço da produção nacional $(36,3 \%)$ têm origem nos pequenos negócios.

Segundo dados do Sebrae e do DIEESE (2018), no ano de 2016, o segmento de MPEs no Brasil representava cerca de 6,8 milhões de estabelecimentos, sendo estes responsáveis pela geração de 16,9 milhões de empregos formais. Mesmo com o processo de queda da produção e o aumento do desemprego no país, os micro e pequenos empreendimentos tiveram um papel significativo na geração de postos de trabalho, contribuindo assim para a economia.

No período compreendido entre 2006 e 2016, o número de MPEs cresceu 21,9\%. Em 2016, especificamente, 99\% dos estabelecimentos enquadravam-se como MPEs e eram responsáveis por mais da metade dos empregos com carteira assinada (SEBRAE; DIEESE, 2018). Salientando a representatividade das MPEs, o gráfico 2 apresenta um comparativo da evolução do número de MPEs em relação às Médias e Grandes Empresas (MGEs) no Brasil.

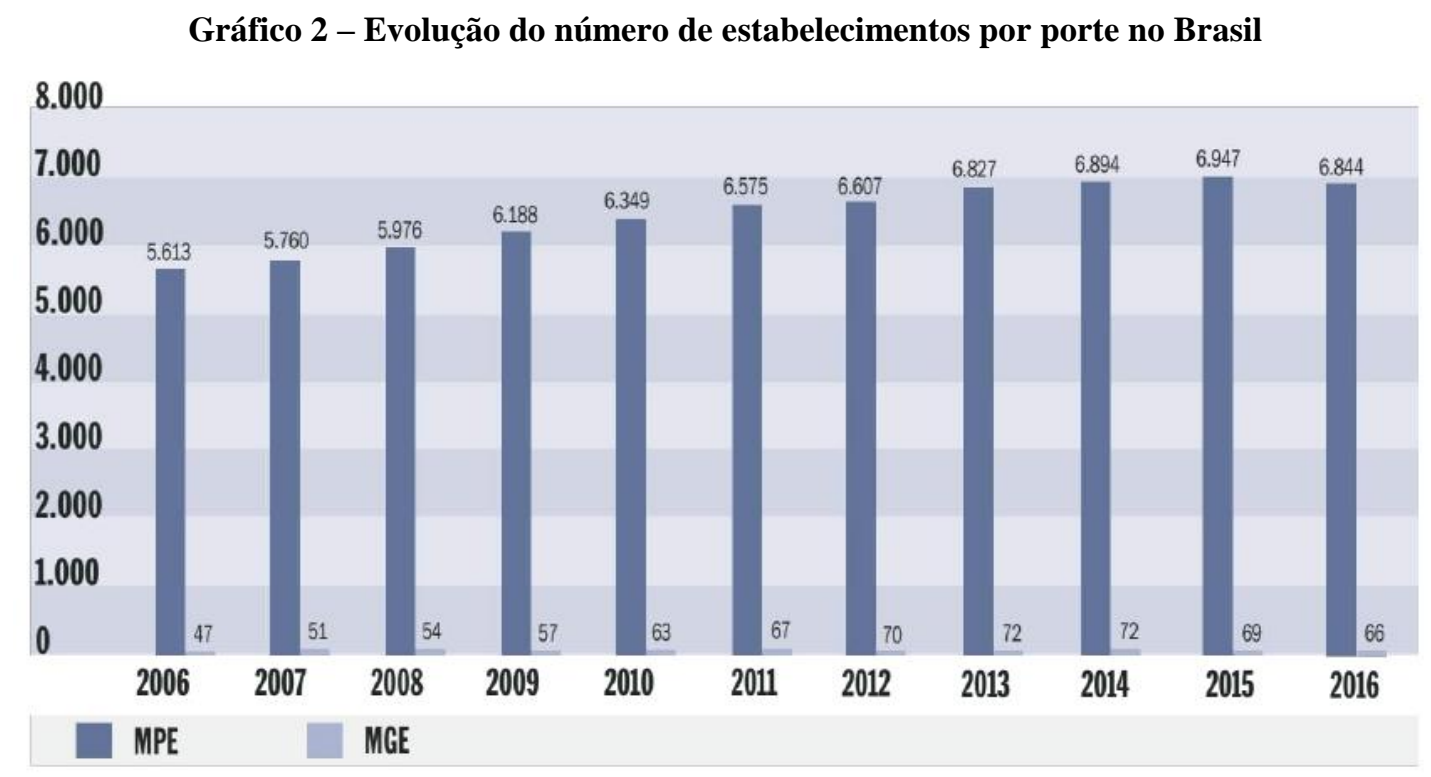

Fonte: SEBRAE; DIEESE (2018)

Apesar dos níveis significativos de crescimento apresentados desde o início da década de 2000, a recessão econômica iniciada em 2014 afetou o desempenho econômico das MPEs. Diante deste cenário, inúmeros estabelecimentos foram fechados e geração de empregos e de renda apresentou queda. No entanto, mesmo em meio as dificuldades vivenciadas nos últimos 


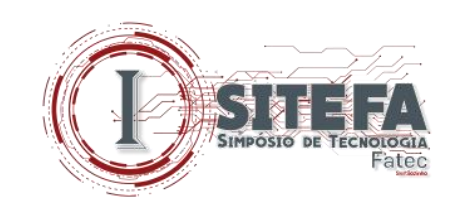

anos, as MPEs, de modo geral, mostraram-se resilientes e contribuíram para amenizar os impactos da crise no mercado de trabalho e na estrutura produtiva (SEBRAE; DIEESE, 2018).

\subsection{O conceito global da administração financeira nas organizações}

De acordo com Gitman (2009, p. 2), “o termo finanças pode ser definido como a arte e a ciência de administrar o dinheiro". Neste contexto, é possível ressaltar que praticamente todas as pessoas físicas e jurídicas capazes legalmente gastam ou investem dinheiro, gerando assim movimentações financeiras que conduzem os mercados a atuarem e criarem estratégias globais. As finanças, deste modo, permeiam todas as atividades pessoais e organizacionais.

No mundo globalizado e contingente vivenciado no cenário contemporâneo das organizações e da sociedade, a administração financeira vem assumindo uma importância cada vez maior. Deste modo, o planejamento e o controle das atividades empresariais estão diretamente condicionados às dinâmicas financeiras nas quais as organizações e seus atores mercadológicos operam e estão inseridos (LEMES JUNIOR; RIGO; CHEROBIM, 2016).

Lemes Junior, Rigo e Cherobim (2016, p. 14), ainda enfatizam que "[...] a administração financeira ocorre em empresas de todos os portes, naturalmente os enfoques são diferentes, mas os princípios de transparência e maximização de resultados devem estar presentes desde a microempresa até as grandes empresas".

Antonik (2015) ressalta que, no âmbito organizacional, a gestão financeira refere-se ao planejamento, a organização e a prevenção de riscos ou de situações indesejáveis no futuro. Neste sentido, Ching, Marques e Prado (2010, p. 178) ressaltam que "a gestão financeira de qualquer empresa deve ser cuidadosamente planejada, executada e acompanhada".

Os autores ainda ressaltam que a gestão financeira se caracteriza como uma atividade indispensável para qualquer tipo de empreendimento atuante na economia capitalista contemporânea, independente do modelo de negócios a qual o mesmo está submetido. A figura 1 representa, de modo generalizado, as principais funções da administração financeira. 


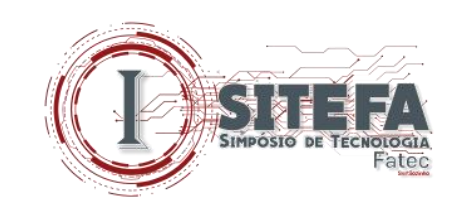

Figura 1 - As principais funções da administração financeira nas organizações

\begin{tabular}{|lll|}
\hline \multicolumn{1}{|c|}{ GERENCIA FINANCEIRA } & \multicolumn{1}{c|}{ CONTROLADORIA } \\
\hline - Administração de caixa & - Administração de custos e preços \\
- Administração de crédito e cobrança & - Auditoria interna \\
- Administração do risco & - Avaliação de desempenho \\
- Administração de câmbio & $\cdot$ Contabilidade \\
- Decisão de financiamento & - Orçamento \\
- Decisão de investimento & Patrimônio \\
- Planejamento e controle financeiro & Planejamento tributário \\
- Relações com acionistas e investidores & - Relatórios gerenciais \\
- Relações com bancos & - Sistemas de informação financeira \\
\hline
\end{tabular}

Fonte: Lemes Junior, Rigo e Cherubim (2016)

Para Megliorini (2012), a administração financeira tem como principal objetivo gerenciar os recursos financeiros da empresa, aplicando-os de acordo com as necessidades organizacionais ligadas aos processos estratégicos e decisórios em geral. Tratar das finanças, deste modo, é considerado algo essencial, independente do segmento ou porte da organização.

Megliorini e Vallim (2009) afirmam que, juntamente com a administração de pessoal, de marketing, de materiais e de produção, a gestão financeira compõe as cinco grandes áreas da administração empresarial no cenário mundial. Cada uma delas, de modo sistêmico, executam integradamente as funções de planejamento, organização, direção e controle.

Para Ross et al. (2013), no âmbito dos negócios organizacionais como um todo, o principal objetivo da administração financeira é focar a obtenção de lucros e agregar valor aos proprietários das empresas. Ainda na contextualização dos objetivos centrais da gestão financeira, Megliorini e Valim (2009) complementam que uma das principais competências da administração financeira é gerir racionalmente os recursos financeiros das organizações.

Nesta perspectiva, Chiavenato (2014, p. 2), ressalta que "as empresas são organizações sociais que utilizam dinheiro, recursos e competências para entregar algo ao mercado e atingir determinados objetivos". As mesmas, deste modo, interagem com o meio onde se inserem.

A gestão financeira, em sua base de atuação, deve manter um estreito relacionamento com as demais áreas da organização, buscando assim a interação dos processos gerenciais e decisórios. São os recursos financeiros, em sua essência, que fornecem a possibilidade de as 


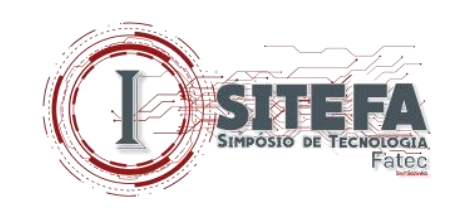

organizações adquirirem os elementos necessários para o desenvolvimento de suas atividades junto ao segmento no qual estão inseridas (CHIAVENATO, 2014).

\subsection{Particularidades de planejamento e controle financeiro nas MPEs}

Segundo Cunha (2002), diante de um mercado competitivo e dinâmico, é fundamental que as empresas de micro e pequeno porte possuam uma estrutura administrativa adequada e organizada. Tal fato envolve controles específicos das rotinas administrativas e a aplicação de ferramentas gerenciais no âmbito financeiro, analisando a organização sob um viés amplo.

Para Santos (2001), a administração financeira das MPEs sempre se caracterizou como algo simplista e pouco especializado, consistindo somente em atividades que envolviam processos de pagamentos e recebimentos. Por este motivo, a gestão financeira dos micro e pequenos empreendimentos era considerada uma simples extensão da administração geral. Ao longo dos anos, contudo, este quadro vem sofrendo transformações. A gestão financeira dos pequenos negócios, deste modo, passou a obter maior relevância e abrangência de aplicação.

Para Leone (1999), as MPEs são caracterizadas por um baixo nível de maturidade organizacional. Deste modo, os processos de planejamento e controle das mesmas tendem a ser pouco formalizados. Megliorini e Vallim (2009) ressaltam que, em muitas empresas de pequeno porte, a estrutura organizacional das mesmas não possibilita a existência de um setor específico de finanças. Com isso, os próprios empreendedores, a maioria sem possuir conhecimentos técnicos suficientes, acaba desempenhando funções de um gestor financeiro.

Neste cenário, Azevedo e Leone (2011) afirmam que as MPEs são organizações nas quais predomina um modelo de gestão financeira empírico, em virtude de dificuldades no acesso aos dados e informações necessárias para obter um nível de controle gerencial eficaz.

Mediante este panorama, torna-se natural que os aspectos referentes aos controles financeiros apresentem estruturas simplificadas inicialmente. Ao longo do tempo, no entanto, é fundamental que tais controles sejam mais efetivos e aprimorados, implementando assim uma administração financeira devidamente capaz de conduzir os rumos da organização.

De acordo com Chiavenato (2014), as mudanças ocorridas no âmbito econômico mundial exigem dos gestores uma visão cada vez mais ampla, sistêmica e aprofundada sobre a realidade financeira das quais as suas empresas vivenciam. Diante deste cenário, a gestão 


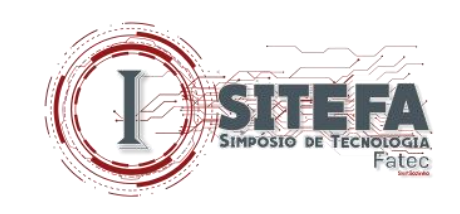

financeira se caracteriza como uma das principais ferramentas empresariais a fim de viabilizar a competitividade das organizações, tendo como ênfase as micro e pequenas empresas.

Na perspectiva de Santos (2001), a administração financeira tem sido de importância crescente para as empresas de micro e pequeno porte. Neste sentido, o sucesso empresarial depende cada vez mais do uso de práticas e ferramentas financeiras apropriadas visando garantir uma gestão organizacional qualificada.

Dentre as principais ferramentas de gestão financeira das MPEs, o fluxo de caixa é considerado uma das mais importantes. Através de sua utilização, os gestores controlam as entradas e saídas de recursos financeiros que ocorrem na empresa. A figura 2 apresenta um modelo de fluxo de caixa tradicional nas organizações, mas que também pode ser utilizado na esfera das MPEs devido a sua facilidade de aplicação.

Figura 2 - Modelo de fluxo de caixa utilizado na gestão financeira

\begin{tabular}{|c|c|}
\hline ENTRADAS & VALORES \\
\hline Entradas em dinheiro & $\mathrm{R} \$ 2.500,00$ \\
\hline Entradas em cheque à vista & $\mathrm{R} \$ 2.000,00$ \\
\hline Entradas cheque à prazo & $\mathrm{R} \$ 1.800,00$ \\
\hline TOTAL ENTRADAS & $\mathbf{R} \$ 6.300,00$ \\
\hline SAÍDAS & VALORES \\
\hline Retiradas do(s) proprietário(s) ${ }^{*}$ & $\mathrm{R} \$ 500,00$ \\
\hline Depósitos bancários & $\mathrm{R} \$ 500,00$ \\
\hline Pagamento a fornecedores (produtos/matéria-prima) & $\mathrm{R} \$ 400,00$ \\
\hline Pagamento a fornecedores (água, luz, aluguel, etc.) & $\mathrm{R} \$ 150,00$ \\
\hline Pagamento a fornecedores (serviços prestados) & $\mathrm{R} \$ 200,00$ \\
\hline Pagamento de tributos (impostos, taxas, etc.) & $\mathrm{R} \$ 80,00$ \\
\hline TOTAL SAÍDAS & $\mathbf{R} \$ 1.830,00$ \\
\hline SALDO INICIAL DE CAIXA* & $\mathrm{R} \$ 2.000,00$ \\
\hline SALDO FINAL DE CAIXA & $R \$ 6.470,00$ \\
\hline
\end{tabular}

Fonte: Adaptado de Sebrae (2018)

Segundo Cunha (2002), os gestores das MPEs se deparam frequentemente com problemas para separar os recursos pessoais dos empresariais. Diante deste contexto, é muito comum encontrar empresas que são geridas de forma simples e sem controles financeiros consistentes. Tal fato, contudo, é prejudicial para a continuidade dos negócios a longo prazo. 


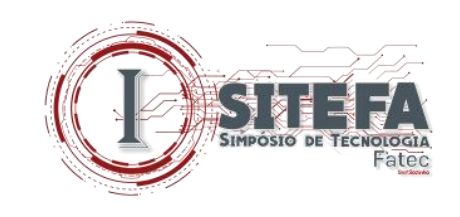

Devido à ausência ou a ineficiência de sistemas de planejamento financeiro e de apuração de resultados, os números obtidos e analisados pelos administradores podem não lhes fornecerem informações precisas sobre o desempenho da empresa, acarretando assim em problemas no seu processo gerencial e nas decisões executadas.

Segundo Marques (2009), os empreendimentos de micro e pequeno porte possuem características peculiares que os diferem das grandes empresas, tais como visão de curto prazo, capacidade financeira reduzida e falta de qualificação por grande parte dos seus administradores. Todos os itens apontados prejudicam a sustentabilidade e o desenvolvimento das MPEs, tornando evidente a necessidade da adoção de mecanismos que minimizem os erros cometidos por seus gestores, tendo como ênfase a solidez da gestão financeira.

\begin{abstract}
Na maioria das micro e pequenas empresas, encontramos uma má administração dos recursos financeiros. Os empresários ainda não têm uma mentalidade de planejamento. Isso dificulta muito a sobrevivência da empresa, pois, estas geralmente não possuem grandes reservas de capital, e ao encontrar as primeiras pedras no seu caminho, não estão preparadas e acabam caindo. É importante ressaltar que os empresários devem estar atentos aos mecanismos que utilizam no planejamento e acompanhamento do desempenho das empresas (ROSA; LIMA, 2008, p. 3).
\end{abstract}

Para Marques (2009, p. 5), “a escassez de recursos financeiros e o elevado custo para sua captação, juntamente com a falta de planejamento e controle, têm contribuído para que muitas empresas encerrem suas atividades, principalmente as micro e pequenas empresas".

Neste sentido, Rosa e Lima (2008) ressaltam que a sobrevivência e o desenvolvimento das empresas em geral, em especial as de micro e pequeno porte, estão diretamente condicionados a adoção de um planejamento financeiro eficiente, no qual se destaca o controle frequente das receitas e despesas e a projeção contínua do fluxo de caixa e seu giro.

Ao gerenciar os seus recursos e atividades financeiras adequadamente, os micro e pequenos empresários visam garantir a viabilidade e a competitividade de seus empreendimentos no mercado. Pode-se ressaltar, com isso, que a gestão financeira ineficiente é uma das principais causas de insucesso das MPEs contemporâneas. Diante do exposto, verifica-se que a sobrevivência dos micro e pequenos negócios é fundamental visando garantir a sustentação do desenvolvimento econômico e social do país (ROSA; LIMA, 2008). 


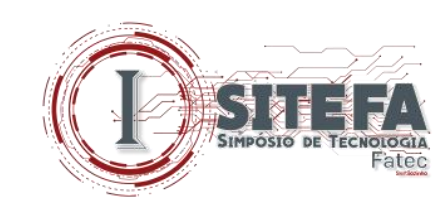

\section{METODOLOGIA DE PESQUISA}

O trabalho científico em questão foi elaborado mediante pesquisa bibliográfica. Nesta modalidade de procedimento metodológico, o principal intuito foi reunir abordagens complementares de diversos autores da área de finanças empresariais, tendo como ênfase aplicá-las junto à realidade administrativa e operacional dos micro e pequenos negócios.

Segundo Cervo, Bervian e Silva (2007), a pesquisa bibliográfica procura explicar um determinado problema a partir de referências teóricas publicadas em artigos, livros, dissertações e teses acadêmicas. Ela pode ser realizada independentemente ou como parte de pesquisa descritiva ou experimental. Em ambos os casos, busca-se conhecer e analisar as contribuições culturais e científicas do passado sobre determinado assunto, tema ou problema.

Gil (2002) ressalta que a principal vantagem da pesquisa bibliográfica reside no fato de a mesma permitir ao investigador a cobertura de uma gama de fenômenos muito mais ampla do que aquela que o mesmo poderia obter caso pesquisasse algum objeto diretamente.

\section{RESULTADOS E DISCUSSÃO}

De acordo com Oliveira (2006), as micro e pequenas empresas (MPEs) desempenham um papel de fundamental importância no contexto econômico contemporâneo. No processo de desenvolvimento social e mercadológico como um todo, é expressiva a contribuição que os micro e pequenos empreendimentos prestam ao gerarem oportunidades para o aproveitamento de uma grande parcela de força de trabalho e ao estimularem o fortalecimento empresarial.

De acordo com Santos (2001), diante do cenário empresarial contemporâneo e em virtude da crescente complexidade econômica e mercadológica, modernos mecanismos foram exigidos para garantir o desenvolvimento da gestão financeira dos micro e pequenos negócios. Com isso, novas vertentes vêm sendo abordadas visando otimizar as atividades empresariais.

Segundo Padoveze e Martins (2014), para um empreendimento de micro ou pequeno porte obter sucesso junto ao segmento de negócios no qual atua, é necessário que o mesmo planeje e gerencie as suas atividades financeiras com o maior nível de controle possível. Desta forma, a estruturação da gestão financeira é fundamental para organizações de qualquer porte. No entanto, a mesma possui uma representatividade ainda mais significativa junto aos micro e pequenos empreendimentos, que devem priorizá-la de maneira contínua em seus negócios. 


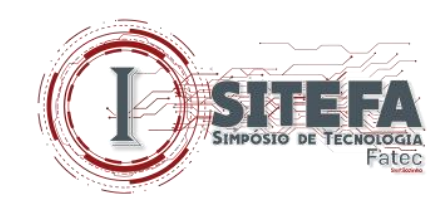

De acordo com Marques (2009), o planejamento financeiro é o processo que conduz os micros e pequenos empresários a acompanhar as diretrizes de mudanças de seus negócios e a rever, quando necessário, as metas já estabelecidas. Megliorini (2012) complementa que, no âmbito das MPEs, é essencial que os gestores recebam orientações provenientes do ambiente externo, visando otimizar a administração de suas finanças e de seus negócios como um todo.

Diante deste contexto, os gestores das MPEs devem possuir um conhecimento adequado sobre as particularidades financeiras que envolvem os seus empreendimentos. A ausência de uma base de conhecimentos sólida sobre a estrutura financeira das organizações tende a acarretar numa grande dificuldade de manutenção e sobrevivência das mesmas junto ao ambiente mercadológico no qual participam e se desenvolvem (OTT et al., 2014).

\section{CONSIDERAÇÕES FINAIS}

Ao analisar o cenário econômico dinâmico e repleto de incertezas vivenciado pelo Brasil na última década, visualiza-se que as micro e pequenas empresas precisam estar preparadas para conduzirem os seus negócios com o máximo de eficácia e competitividade.

Mediante este panorama, a gestão adequada dos recursos financeiros assume um papel de extrema importância no âmbito funcional e estratégico das MPEs, sendo um fator essencial para a continuidade e a competitividade das mesmas a longo prazo. A adoção de ferramentas de planejamento e controle, neste contexto, são essenciais para as MPEs compreenderem os fatores internos e externos que impactam as suas operações e ações estratégicas em geral.

Diante desta perspectiva, é fundamental que os micro e pequenos empresários compreendam a relevância de gerir corretamente o campo financeiro, visando assim garantir a manutenção de seus negócios. Considera-se, desta forma, que o gerenciamento inadequado dos recursos financeiros por parte dos empreendedores é um dos principais responsáveis pelo encerramento precoce das atividades de inúmeras micros e pequenas empresas no Brasil.

$\mathrm{Na}$ esfera analítica dos micro e pequenos empreendedores, portanto, é essencial que os mesmos compreendam a importância da utilização de ferramentas financeiras para contribuir na otimização de suas atividades. Neste contexto, a amplitude proporcionada pelas ações de planejamento e controle são essenciais não apenas para delinear os objetivos financeiros das MPEs, mas também para estruturar a visão global das mesmas sobre o cenário em que atuam. 


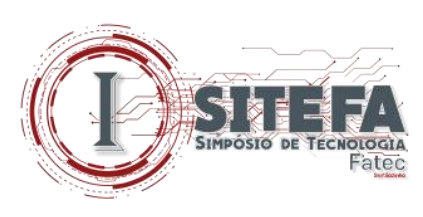

\section{REFERÊNCIAS}

ANTONIK, L.R. Empreendedorismo: gestão financeira para micro e pequenas empresas. Rio de Janeiro: Alta Books, 2015.

AZEVEDO, J.G.; LEONE, R.J.G. Práticas de gestão financeira em micro e pequenas empresas: um estudo descritivo em indústrias de castanha de caju do Estado do Rio Grande do Norte. Revista Ciência Administrativa, Fortaleza, CE, v. 17, n. 1, p. 55-83, 2011. Disponível em: <http://periodicos.unifor.br/rca/article/view/3221/pdf> Acesso em: 22 set. 2018.

BRASIL. Lei Complementar $\mathbf{n}^{0}$ 123, de 14 de dezembro de 2006. Institui o Estatuto Nacional da Microempresa e da Empresa de Pequeno Porte; altera dispositivos das Leis no 8.212 e 8.213. Disponível em: 〈http://www.planalto.gov.br/ccivil_03/leis/LCP/Lcp123.htm> Acesso em 28 ago. 2016.

CAMPOS, C.C. 10 anos do Simples Nacional. Caderno FGV Projetos, Rio de Janeiro, RJ, v. 11, n. 29, 2016. Disponível em:

<https://fgvprojetos.fgv.br/sites/fgvprojetos.fgv.br/files/caderno_simples_nacional_bx.pdf> Acesso em: 22 set. 2018.

CERVO, A.L.; BERVIAN, P.A.; SILVA, R. Metodologia científica. 6. ed. São Paulo: Pearson Prentice Hall, 2007.

CHIAVENATO, I. Gestão financeira: uma abordagem introdutória. 3. ed. Barueri: Manole, 2014.

CHING, H.Y.; MARQUES, F.; PRADO, L. Contabilidade \& Finanças para não especialistas. 3.ed. São Paulo: Pearson, 2010.

CUNHA, M.A.N. O perfil da administração financeiras das pequenas e médias empresas. 2002. 95 f. Dissertação (Mestrado em Administração Pública). Fundação Getúlio Vargas (FGV). Rio de Janeiro. Disponível em:

<http://bibliotecadigital.fgv.br/dspace/bitstream/handle/10438/8061/000317971.pdf?sequence =1> Acesso em: 22 set. 2018 .

GIL, A.C. Como elaborar projetos de pesquisa. 4.ed. São Paulo: Atlas, 2002.

GITMAN, L.J. Princípios de Administração Financeira. 12.ed. São Paulo: Pearson, 2010.

LEMES JUNIOR, A.B.; RIGO, C.M.; CHEROBIM, A.P.M.S. Administração financeira: princípios, fundamentos e práticas brasileiras. 4.ed. Rio de Janeiro: Elsevier, 2016.

LEONE, N.M.C.P.G. As especificidades das pequenas e médias empresas. Revista de Administração, São Paulo, SP, v. 34, n. 2, p. 91-94, 1999. Disponível em: 


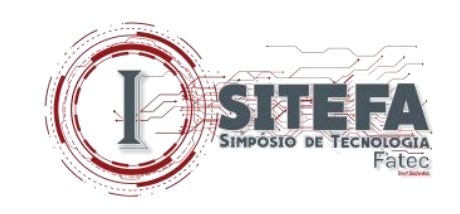

$<$ http://www.spell.org.br/documentos/ver/18123/as-especificidades-das-pequenas-e-mediasempresas> Acesso em: 24 set. 2018.

MARQUES, A.V. Planejamento e controle financeiro nas micro e pequenas empresas visando a continuidade e a sustentabilidade. In: XXIX Encontro Nacional de Engenharia de Produção (ENEGEP), Salvador, BA, 2009. Disponível em:

<http://www.abepro.org.br/biblioteca/enegep2009_tn_sto_093_630_14278.pdf> Acesso em: 20 set. 2018.

MEGLIORINI, E. Administração Financeira. São Paulo: Pearson, 2012.

E.; VALLIM, M.A. Administração Financeira: Uma abordagem brasileira. São

Paulo: Pearson Prentice Hall, 2009.

OLIVEIRA, O.J. Pequena empresa no Brasil: Um estudo de suas características e perspectivas. Revista Integração, São Paulo, SP, v. 12, n. 44, p. 5-16, 2006.

OTT, J.N.; et al. Mortalidade precoce das empresas e a sua importância para a economia. In: XXII Seminário de Iniciação Científica (UNIJUI), Ijuí, RS, 2014. Disponível em: $<$ https://www.publicacoeseventos.unijui.edu.br/index.php/salaoconhecimento/article/view/36 07/0> Acesso em: 22 set. 2018.

PADOVEZE, C.L.; MARTINS, M.A.M. Contabilidade e Gestão para Micro e Pequenas Empresas. Curitiba: Intersaberes, 2014.

ROSA, J.A.; LIMA, R.A. A importância do planejamento financeiro para micro e pequenas empresas. In: XII Encontro Latino Americano de Iniciação Científica e VIII Encontro Latino Americano de Pós-Graduação (Universidade do Vale da Paraíba), São José dos Campos, SP, 2008. Disponível em:

<http://www.inicepg.univap.br/cd/INIC_2008/anais/arquivosINIC/INIC1213_01_O.pdf> Acesso em: 30 ago. 2016.

ROSS, S.A.; et al. Fundamentos de administração financeira. 9.ed. Porto Alegre: AMGH, 2013.

SANTOS, E.O. Administração Financeira da Pequena e Média Empresa. São Paulo: Atlas, 2001.

SEBRAE. As pequenas empresas do Simples Nacional. Brasília, 2011. Disponível em: <http://www.sebrae.com.br/Sebrae/Portal\%20Sebrae/Anexos/As_pequenas_empresas_SN.pdf $>$ Acesso em: 22 set. 2018.

Participação das Micro e Pequenas Empresas na economia brasileira. Brasília, 2014. Disponível em: 


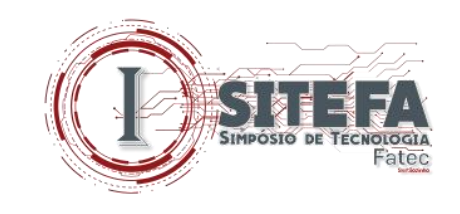

$<$ http://www.sebrae.com.br/Sebrae/Portal\%20Sebrae/Estudos\%20e\%20Pesquisas/Participaca o\%20das\%20micro\%20e\%20pequenas\%20empresas.pdf> Acesso em: 22 set. 2018.

Fluxo de caixa: o que é e como implantar. 2015. Disponível em:

<http://www.sebrae.com.br/sites/PortalSebrae/artigos/fluxo-de-caixa-o-que-e-e-comoimplantar,b29e438af1c92410VgnVCM100000b272010aRCRD> Acesso em: 27 set. 2018.

; DIEESE. Anuário do Trabalho na Micro e Pequena Empresa: 2012. 5.ed.

Brasília: DIEESE, 2012. Disponível em:

<https://www.dieese.org.br/anuario/2012/anuarioSebrae.html> Acesso em: 22 set. 2018.

DIEESE, 2018. Disponível em:

Anuário do trabalho nos pequenos negócios: 2016. 9.ed. São Paulo:

<https://www.dieese.org.br/anuario/2018/anuarioDosTrabalhadoresPequenosNegocios.pdf> Acesso em: 27 set. 2018.

TOZZINI, S. A administração financeira na pequena empresa: realidade ou ficção? Augusto Guzzo Revista Acadêmica, São Paulo, SP, v. 1, n. 3, p. 85-92, 2001. Disponível em:

<http://www.fics.edu.br/index.php/augusto_guzzo/rt/captureCite/97/109> Acesso em: 20 set. 2018.

VILGA, V.F.; FARAH, O.E.; GIULIANI, A.C. Pequenas empresas: a má administração e a alta taxa de mortalidade. In: IV Encontro de Estudos sobre Empreendedorismo e Gestão de Pequenas Empresas (EGEPE), Curitiba, PR, 2005. Disponível em:

<http://www.dad.uem.br/graduacao/adm/graduacao/download/2762-39.pdf> Acesso em: 29 set. 2018. 